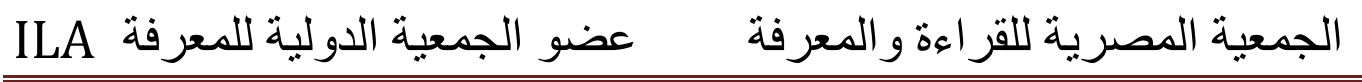

\section{الشخصية في المجتمع المصري}

\author{
إعداد - - اد \\ أ / ندى طارق محمود محمود السلاموني \\ المسجلة لدرجة الماجستير في الآداب قسم علم الاجتماع
}

إشراف:

د/ صبري بديع عبدالمطلب الاجماع

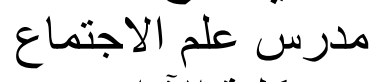

كلية الآداب

جامعة دمباط

\author{
أ.د/ محمود عبدالحميد حسين علي \\ كمال

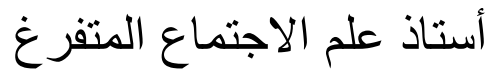

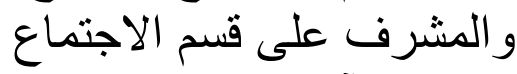 \\ بكلية الآداب جامعة دمياط
}




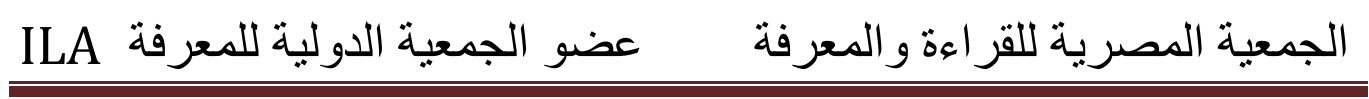




\section{الجمعية المصرية للقر اءة و المعرفة عضو الجمعية الدولية للمعرفة}

مقدمة:

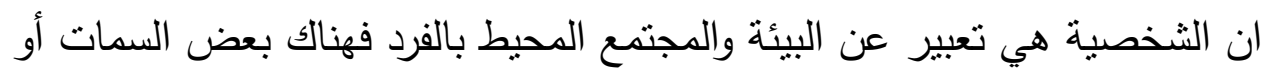

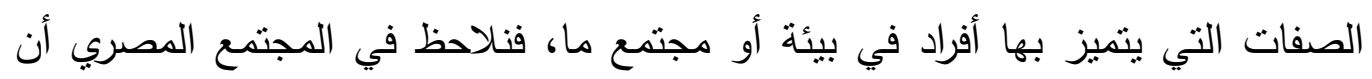

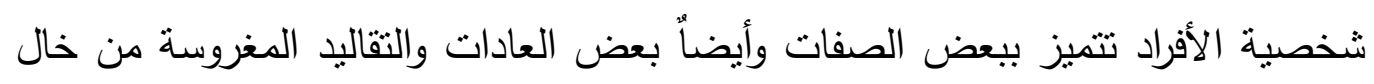

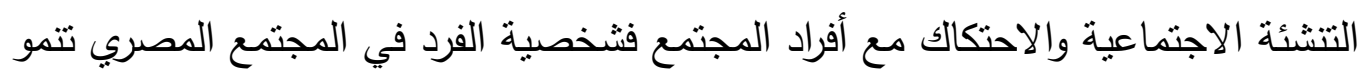

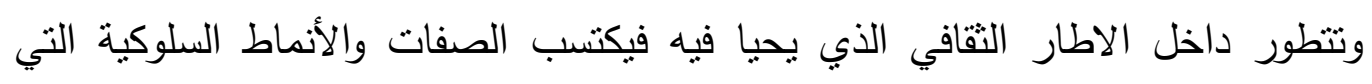

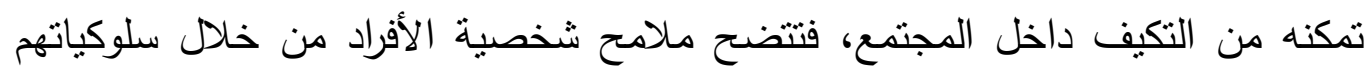

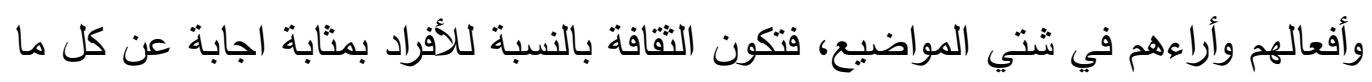

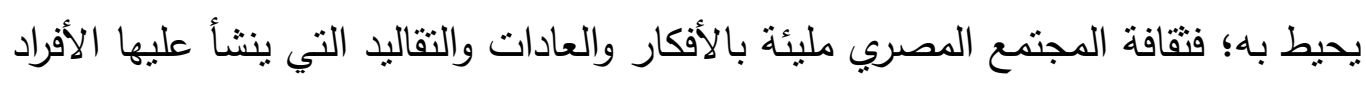

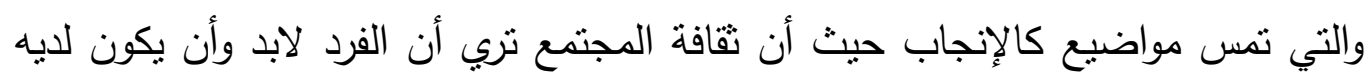

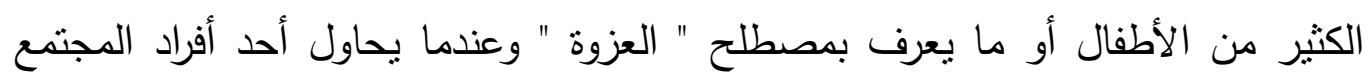

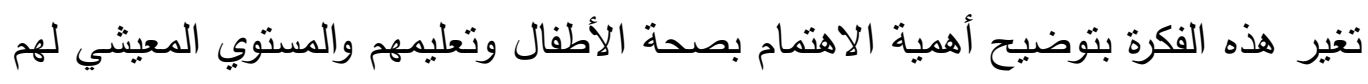

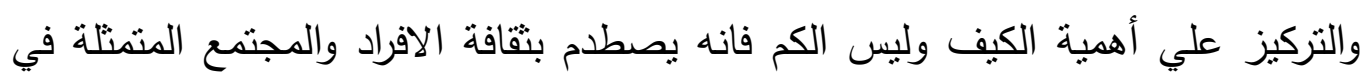

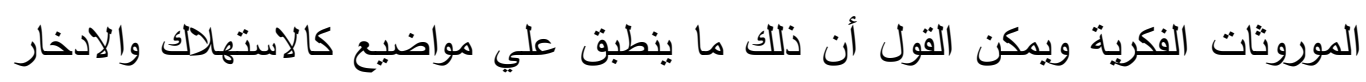
وعدم الوعي بأهميتهم ودي تأثيرهم علي حياتتا.

الثخصية المصرية انعكاس للواقع الاجتماعي والاقتصادي والسياسي لا تتفصل عن

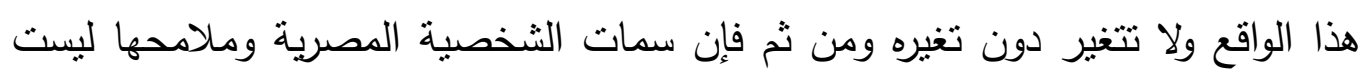

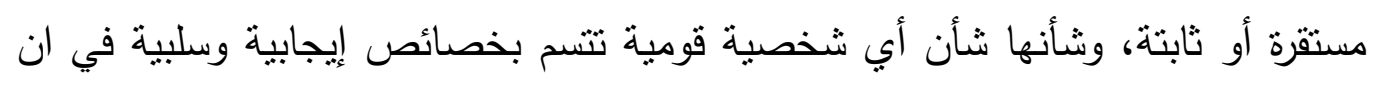

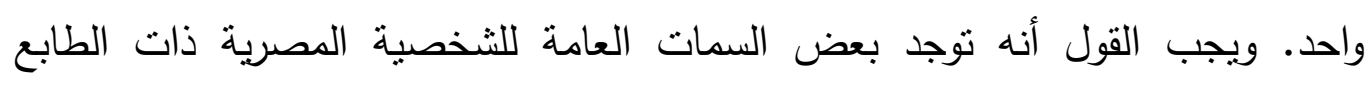

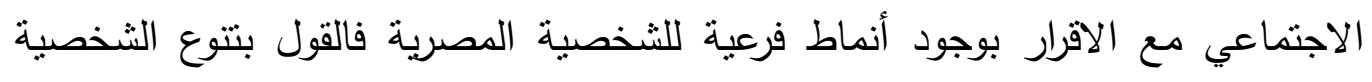

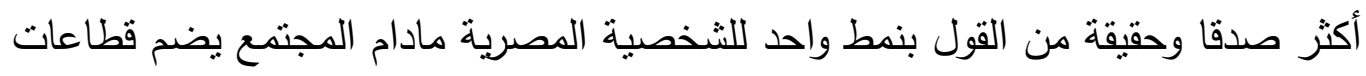

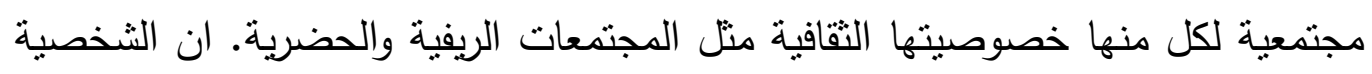

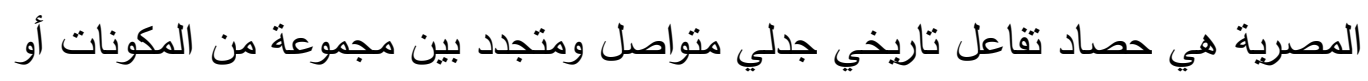




\section{الجمعية المصرية للقر اعة والمعرفة عضو الجمعية الدولية للمعرفة المي}

الركائز المشتركة للشخصية المصرية مسلم ومسيحي ريفي وحضري حسب الطبقات الاجتماعية وأوضاعها وحسب النوع الاجتماعي ذكور وإناث وحسب الأجيال شباب وكبار ولقد نتجت الركائز المشتركة وتأسست وتواصلت نتيجة لتفاعل الجغرافيا بكل دلالاتها

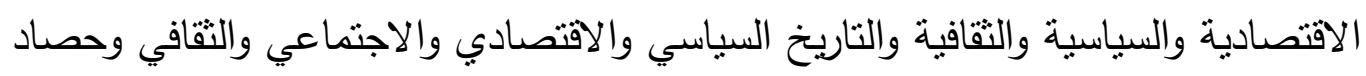

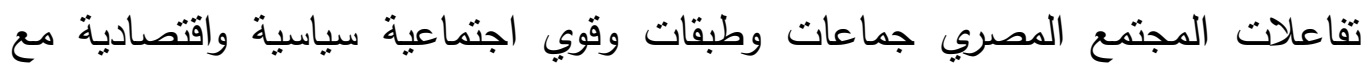
الامكانات الطبيعية والبشرية والتقاعل مع العوامل والقوي الخارجية وعند التدقيق في حصاد

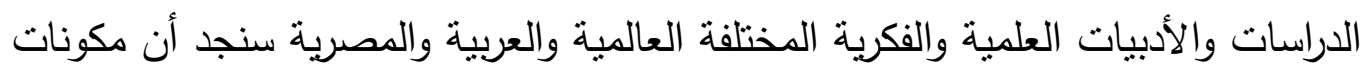
ركائز الثخصية المصرية لا تختلف كثثرا عن ركائز ومقومات الثخصية الوطنية. وإن كان التاريخ السياسي والاقتصادي النوعي هو الذى أكسب الثخصية المصرية طابعها العام المشترك خاصة ما يتعلق بتركيز الثروة والسلطة أو نوزيعهما والعلاقات المرتبطة بهما وبالذات غياب أو حضور المشاركة والديموقراطية والعدالة وتكافؤ الفرص.

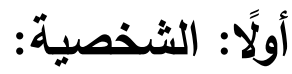

تعريف الثخصية personality مصطلح مشتق من كلمة شخص person والتي تعني بتتكيل كيان الفرد من خلال عملية التقاعل الاجتماعي لتأخذ سمات وخصائص معينة تعبر عن هوية محددة وطابع أو أسلوب مميز في التصرف يكثف عن نظرة الثخص لذاته ورؤيته للأخرين وأساليب التفاعل معهم وتظهر في مجري ممارسات حياته اليومية ومواققه واتجاهاته ازاء الوقائع أو الأحداث الدائرة في العالم الذي يعيش فئهابه، فالثخصية بمعني اخر تعني تنكيل كيان الفرد أي تحويله من كائن بيولوجي له احتياجات

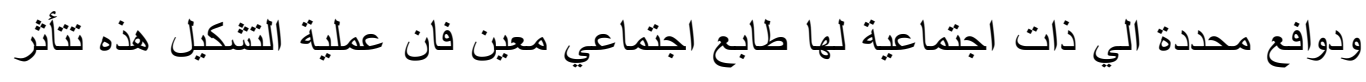
بمجموعة من العوامل المتعددة (بيولوجية ونفسية واجتماعية وثقافية) وتقوم علي التفاعل والترابط بين هذه العوامل التي نتكل كيان الفرد من ناحية والمجال أو البيئة التي يحدث فيها هذا التفاعل أو عملية التشكيل من ناحية اخري ويبدأ تشكيل الثخصية مع عملية 


\section{الجمعية المصرية للقر اءة والمعرفة عضو الجمعية الدولية للمعرفة}

التطبيع الاجتماعي أو التنشئة الاجتماعية ومجموعة الأفكار والتصورات وأساليب السلوك التي تغرسها الأسرة وغيرها من مؤسسات المجتمع في الفرد أو تقرضها عليه وتحدد له لهاته طبيعة الأنشطة التي يمارسها والمكانة التي بشغهانها. كما ارتبط مفهوم الشخصية باسم "كاردنر" وبه 19 وطوره "رالف لينتون" حيث يستند هذا المفهوم عنده الي فرضية أساسية مفادها تباين معايير الثخصية من مجتمع الي اخر ومن ثم يشترك أعضاء المجتمع الواحد في قائمة طويلة من عناصر الثخصية بعبارة

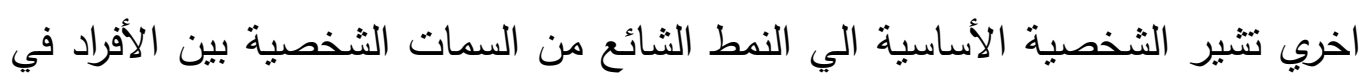

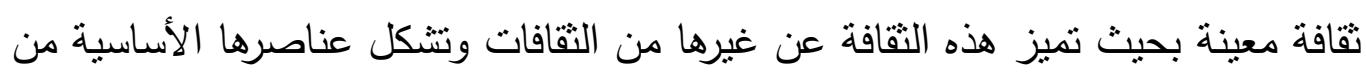
خلال عملية التشئة الاجتماعية حيث تحرص وسائط التتشئة علي نقل عناصر النقافة من

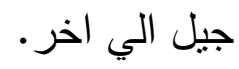

ان الثخصية الانسانية هي نتاج التفاعل الاجنماعي وان مكونات الشخصية تقوم جميعاً علي أسس ثقافية واجتماعية ولهذا كانت دراسة الثخصية لا يمكن أن نكون كاملة

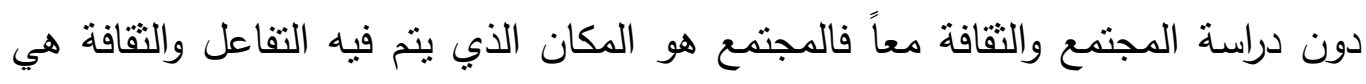
التي تصب هذا التفاعل في قوالب معينة وتعطي للفرد أنماط السلوك ومختلف القيم والمعايير التي يحسن بها التفاعل ويحقق أغراضه،، حقيقة أن الفرد يولد ولا يحمل معه أي

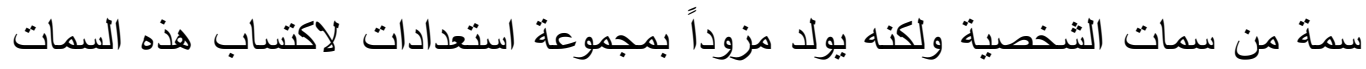
بالتقاعل في المجتمع والالتصاق بالتقافة.

يعرف " لندبرج " الثخصية أنها كل ما يشير الي العادات والاتجاهات والسمات الاجتماعية التي غيرت سلوك فرد معين أي أنها تدل علي أنساق السلوك التي تكتسب من لنئن

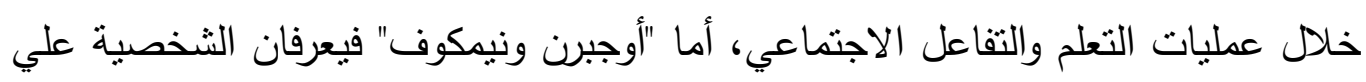
أنها التكامل النفسي والاجتماعي للسلوك عند الكائن الانساني معبراً عنه في عادات ونئن وشعور واتجاهات وأراء. 


\section{الجمعية المصرية للقر اعة والمعرفة عضو الجمعية الدولية للمعرفة المي}

ونجد أن " سو روكين " لا ينكر أهمية الوراثة البيولوجية في الثخصية ولكن يعتقد أن الجانب الاجتماعي الثقافي من الثخصية لا يتحدد أو يكتسب عن طريق هذه الوراثة لأنه يصاغ أو يصب في قالب معين من خلال الوسط الاجتماعي التقافي ويؤكد علي الاتصال المتبادل بين الفرد والتقافة والمجتمع فالفرد يمتص عالمه الثقافي والاجتماعي ويتمتله وينمو علي تربيته وأكد أيضاً أن النمو الفردي مستحيل بدون تتظيم جماعي ويترتب علي ذلك أن الجانب الأكبر من الثخصية الانسانية يرتكز علي دعائم المجتمع لرينه والثقافة.

ويشير مفهوم الثخصية عند " بارسونز " الي العناصر المكونة لبناء الثخصية العادية في المجتمع ولا يشير الي بناء الثخصية الفريدة المتميزة باعتبارها وحدة ملموسة

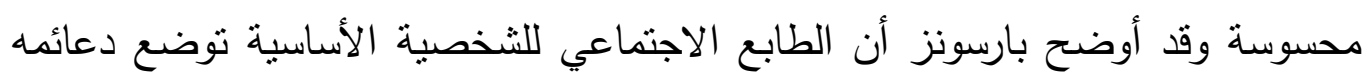
في الطفولة الأولي فليست العناصر التي تككن الثخصية الأساسية عناصر فطرية جينية بل هي عناصر اجتماعية.

ان تعريف الثخصية يشير الي الثكل المنظم نسيباً من أنماط السلوك والاتجاهات والمعتقدات والقيم الذي يثكل الثخص ويجعله قادراً علي ادراك ذاته والاخرين وتعد الثخصية نتائج خبرات الفرد في تفاعله مع بيئته الاجتماعية الثقافية لذا بمكن تحديد بنية شخصية الفرد من خلال ملاحظة النمط العام لسلوكه وكيفية تفكيره ومشاعره وأفعاله بما تحمله ضمنياً من منظومة القيم لديه وتدل شخصية الفرد علي بناء المجتمع وعملياته الذي وني يعيش فيه كما تعكس الثخصية ثقافة الفرد وتمثل في الوقت ذاته الجانب الذاتي للتقافة.

ويعبر " فروم " من خلال مفهوم الطابع الاجتماعي للشخصية عن شخصية المجتمع الذي يشترك غالبية أفراده في ثقافة مشتركة ويتحدد الطابع في ضوء ظروف اقتصادية وأيديولوجية وسياسية بمعني أنه لا يمكن فهم الثخصية القومية الا في ضوه 


\section{الجمعية المصرية للقر اعة و المعرفة عضو الجمعية الدولية للمعرفة}

البناء الاجتماعي وهكذا يعمل الطابع الاجتماعي علي تحقيق وظائف المجتمع كما تحدده

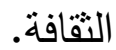

ويشمل بناء الثخصية القومية علي مجموعة من الخصائص والسمات التي تعكس نسق القيم والاتجاهات والمعتقدات والعادات والتقاليد والمشاعر التي تتسم بالاتساق الداخلي والخارجي والمشتركة بين أعضاء مجتمع معين أو التي يؤمن بها قطاع كبير من هذا ولئ المجتمع تجعلهم يسلكون سلوكاً موحداً في مواقف معينة، والثخصية القومية تتسم بالاستمرارية والنسبية لكي تحافظ علي هوية المجتمع، لكنها عرضة التغير وفقاً لتغير البناء الاجتماعي والسياسي والاقتصادي والنقافي.

ويري " مصطفي سويف " أن البناء الأساسي للشخصية القومية هو ذلك النمط من تتظيم الاتجاهات في الشخصية لدي أبناء مجتمع واحد نتيجة لتنابه عمليات التطبيع التي تتصب علي أطفال ذلك المجتمع وترتبط ارتباطاً وثيقاً بالطابع القومي للشخصية، وتري " لئهي سامية الساعاتي " في كتابها بعنوان الثقافة والثخصية بأن الثخصية القومية هي ذلك الجانب من الشخصية الذي يرجع الي عضوية الفرد في قومية معينة أو هي ذلك النمط بان أنهان

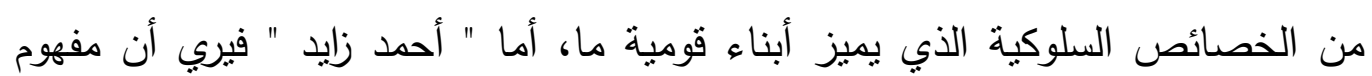
الثخصية القومية أو الطابع القومي يستخدم لوصف الخصائص الثابتة للشخصية وأساليب

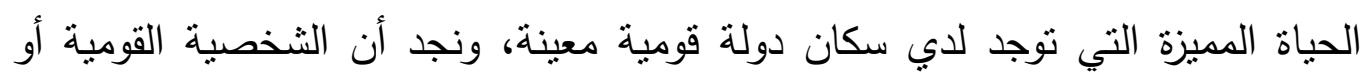

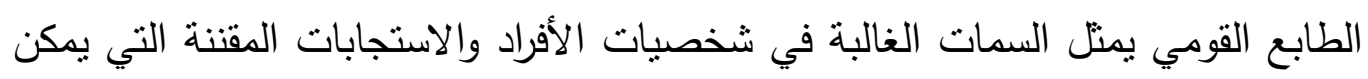

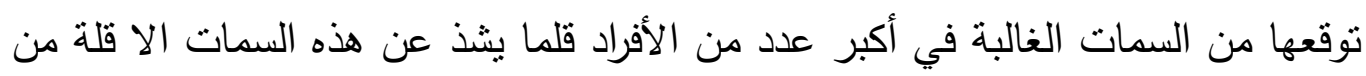
الأفراد.

\section{الشخصية في الأنثرويولوجيا:}

ربط علماء الأنثروبولوجيا التقافية بين النقافة والثخصية وتوصلوا الي أن شخصية الفرد تتحدد من خلال الأطر الثقافية السائدة في المجتمع حيث بيندمج الأفراد من خلال 


\section{الجمعية المصرية للقر اعة والمعرفة عضو الجمعية الدولية للمعرفة المي}

عملية التتشئة الاجتماعية القيم والاتجاهات الأساسية في الثقافة السائدة فتطبع شخصية الفرد علي نحو معين. ومن الأنثروبولوجين الرواد الذين درسوا الثخصية القومية "جورر ولابار وبنديكت ومارجريت ميد وكليد كلاكهون" وقد دفعت الحرب العالمية الثانية الأنثروبولوجيين الي دراسة الثخصية القومية اسهاماً منهم في مساعدة حكوماتهم في فهم الاخر سواء أكان هذا الاخر من الأعداء أو الحلفاء، لكن بعد انتهاء الحرب توقفت هذه

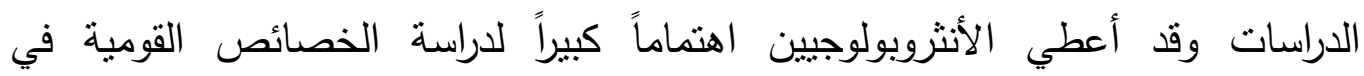

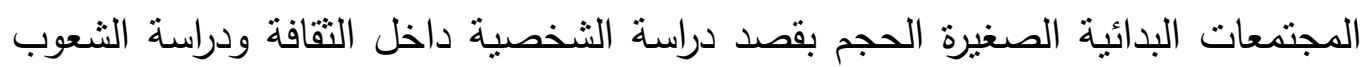

في بيئتها الثقافية .

وطبقاً لآراء "جورر" فان الثخصية القومية هي مجموعة من الصفات الشائعة والسمات المميزة لجماعة من الناس مثل الكرم والثجاعة والسماحة والاخلاص والمهارة في هي العمل والبخل والخبث والكسل وعدم الانجاز والتي تظهر في وسط ثقافي معين.

وأكدت "بنديكت" أن التماسك النفسي بين الأنظمة التي تُكون المجتمع هو الأساس الذي يعيد تقسير الحقائق القومية وتري "بنديكت" أننا يمكن أن نتعرف علي الثخصية القومية اذا تقصينا عن القيم الأكثر شيوعا وأن كل شخص في الدولة يعكس بالضرورة الثخصية القومية.

ويعرف "لينتون" الثخصية أنها التجمع المنظم للحالات والعمليات النفسية المتعلقة بالفرد ويري أن شخصية الفرد هي ثمرة عوامل ثلاثة العنصر البيولوجي الموروث وتأثير

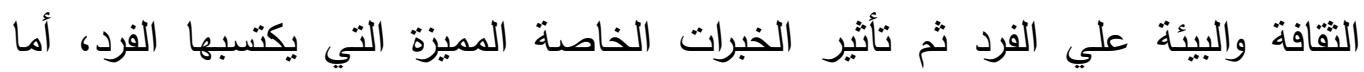
"كاردينر" يعرف الثخصية أنها ذلك الثكل من الثخصية المشترك بين السواد الأعظم من أبناء المجتمع نتيجة خبراتهم السابقة المشتركة.

اذاً تعد الشخصية نتاج خبرات الفرد في تفاعله مع بيئته الاجتماعية الثقافية لذا يمكن تحديد بنية شخصية الفرد من خلال ملاحظة النمط العام لسلوكه وكيفية تفكيره 


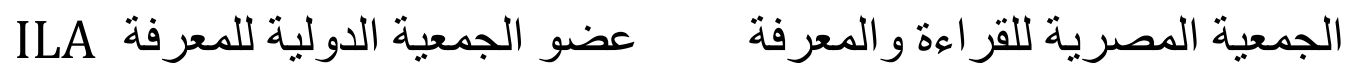

ومشاعره وأفعاله بما تحمله ضمنياً من منظومة القيم لايه وتدل الثخصيات الفردية علي بناء المجتمع وعملياته الذي تعيش فيه كما تعكس الثخصية ثقافة الثخص وتمنل في الوقت ذاته الجانب الذاتي للنقافة.

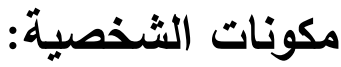

يعتبر العالم "فرويد" هو من أوائل المهتمين بعلم النفس ومن أهم مؤسسيه ولقد نهضت مدرسة التحليل النفسي علي يديه، ويوضح في نظريته وجود حياة نفسية لاشعورية

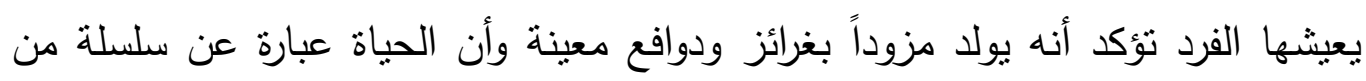
الصراعات تعقبها إثباعات واحباطات.

ولقد قسم فرويد النفس البشرية الي ثلاث مستويات:

$$
\text { الهو: هو منبع الغرائز البشرية. - الأنا - الأنا الأعلى) }
$$

الأنا: هو الثخص نفسه وهي الطبقة الفاصلة بين الهو والأنا الأعلى.

الأنا الأعلى: هو الضمير والغرائز الموجودة اذا صعدت الي الهو يتم اشباعها دون النظر الي أي اعتبارات أخلاقية ودينية ولذلك يوجد الأنا الأعلى الذي يقف رقيب الاعبي بين الفرد وغرائزه.

\section{وفيما يلي سوف نشرح بتفصيل كل منهم:}

(الهو ID : هو الجزء الأساسي الذي ينشأ عنه فيما بعد الأنا والانا الأعلى يتضمن الهو جزئيين: جزء فطري وهي الغرائز الموروثة التي تمد الثخصية بالطاقة بما فيها الأنا والانا الأعلى ، وجزء مكتسب وهي العمليات العقلية المكبوتة التي منعها الانا (الثعور) من الظهور ويعمل الهو وفق مبدأ اللذة وتجنب الألم ولا يراعي

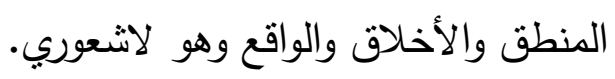




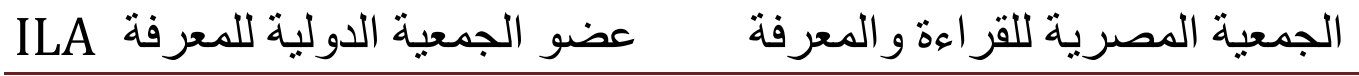

r Fgo الأنا Ego الأنا كما وصفها فرويد هي شخصية المرء في أكثر حالاتها اعتدلاً بين الهو والانا العليا حيث تقبل بعض التصرفات من هذا وذاك وتربطها بقيم

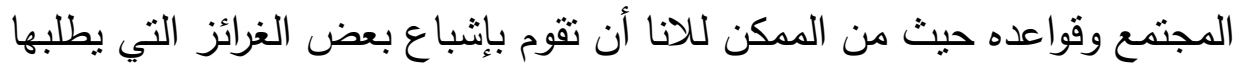

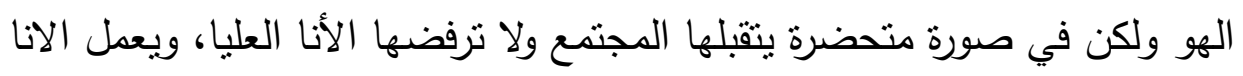

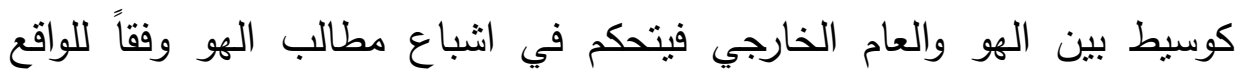
والظروف الاجتماعية وهو يعمل وفق مبدأ الواقع ويمثل الانا الادراك والتفكير والحكمة والملاعمة العقلية ويشرف الأنا علي النشاط الارادي للفرد ويعتبر الانا

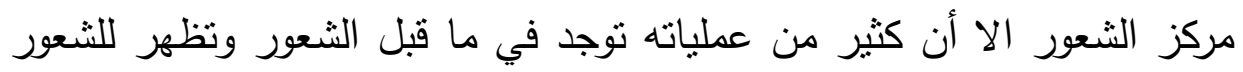

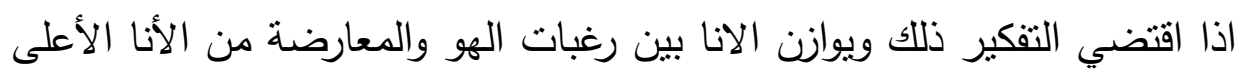
والعالم الخارجي واذا فثل في ذلك أصابه القلق ولجأ الي تخفيفه عن طريق الحيل الحيل

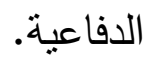

r) الأنا الأعلى Super-Ego: الانا العلبا كما وصفها فرويد هي شخصية المرء

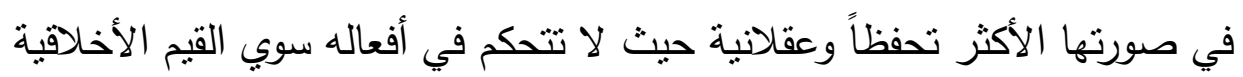

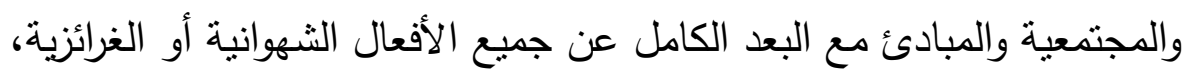

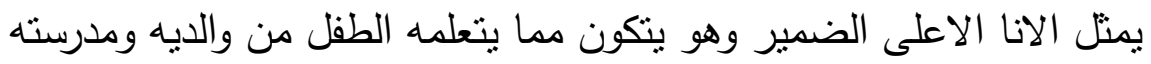

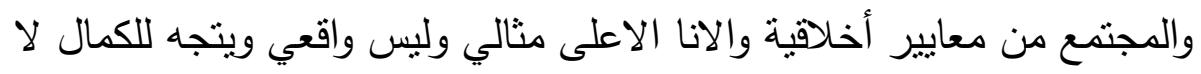
الي اللذة أب أنه يعارض من الهو والانير.

ان أنظمة الثخصية ليست مستقلة عن بعضها ويمكن وصف الهو بأنه الجانب البيولوجي للثخصية والانا بالجانب السيكولوجي للشخصية والانا الاعلى بالجانب

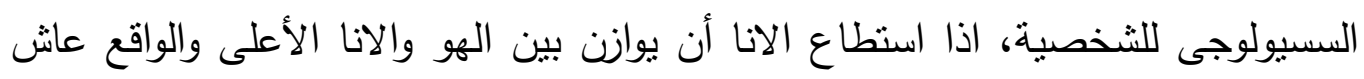

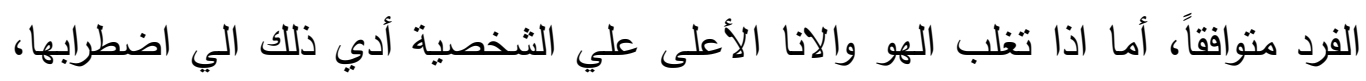

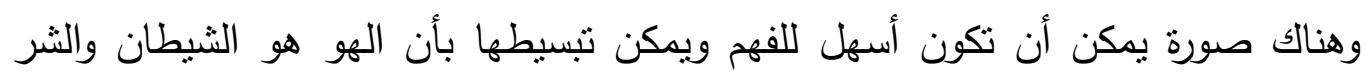

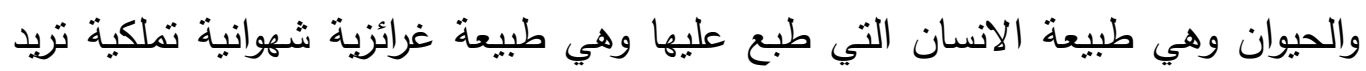




\section{الجمعية المصرية للقر اءة و المعرفة عضو الجمعية الدولية للمعرفة}

الاستحواذ علي كل الثهوات وتتازع من أجل البقاء والسيطرة وتسعي طول حياتها أن تكون حرة بلا رادع أخلاقي أو ديني أو قانوني وبلا أي ضوابط وتمثلها أقلية قليلة من البشر، الثرن أما الأنا العليا فهي النقيض تماماً للهو فهي الملاكك والخير والأخلاق وهي مكتسبة من الأسرة والمجتمع المدني والدولة والدين والانا العليا تتشد الحرية بأن تتحرر من غرائزها ومن الثيطان والثر والنوازع الحيوانية لتسمو عالياً في عالم المبادئ والأخلاق والقيم السامية وتعيش من أجل الغير وهي أقلية قليلة من الناس، وأما الانا فهي التي تثكل حالة وسطية بين الانا الاعلى والهو أي بين الخير والثر بين الملائكية والحيوانية تتصالح

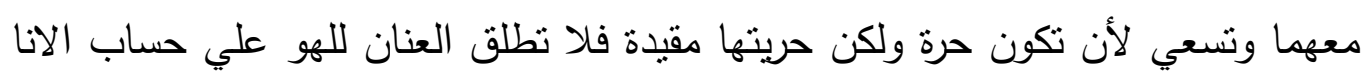
العليا أو لأخري علي حساب الأولي فهي بين بين وهي الغالبية العظمي من البشر.

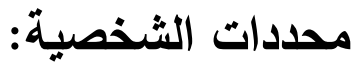

أوضح " كلاكهون ومورى وشنيدر " في كتابهم الثخصية في الطبيعة والمجتمع

والثقافة أن كل انسان في بعض نواحيه:

( ) يشبه كل الناس (معايير كلية عامة)

r) يشبه بعض الناس (معايير جمعية)

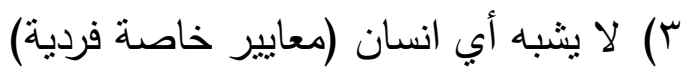

المعايير الكلية: فنحن حين نقول أن شخصاً ما طويل القامة أو سريع الحركة

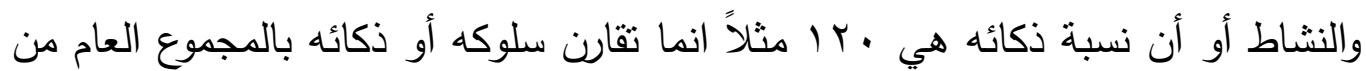
الناس اللذين نعرفهم أو قمنا بقياس أطوالهم أو سرعة نشاطهم أو ذكائهم فهناك معايير موضوعة ويقاس الفرد بالنسبة لها.

المعايير الجمعية والمعايير الكلية: هي في الحقيقة أقرب الي أن تكون معايير جمعية فنحن حين نقارن شخصاً ما في سمة جسمية أو عقلية أو خلقية مثلأ انما نقارنه بمعايير الجماعة التي ينتمي اليها وليس بمعايير عامة للناس جميعاً فاذا قلنا ان هذا 


\section{الجمعية المصرية للقر اعة والمعرفة عضو الجمعية الدولية للمعرفة ILA}

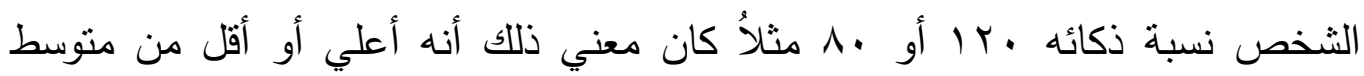
العينة، وهذه المعايير الجمعية مهمة علي وجه الخصوص حين نتحدث عن شخص ما مثناً بأنه من النوع الرياضي أو حالات الهوس والاكتئاب ومثنل هذه العبارات تعني أن لديه مجموعة من الصفات التي لا تختلف كثيراً عن الصفات التي توجد لدي غالبية أفراد الجماعة التي يقارن بها فهذا يعني أنه لا ينتمي الي جماعة مرجعية معينة نريد مقارنته بها

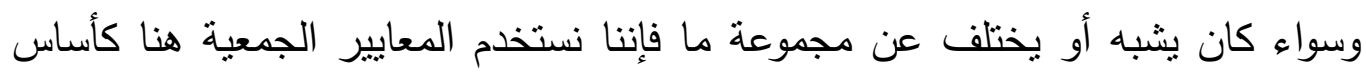
لتقدير طبيعة الفرد.

المعايير الفردية: وبعد أن تصبح أكثر ألفة بشخص ما فإننا نبني توقعانتا بالنسبة له علي أساس وجود تتظيم معين لشخصيته بنسم بالثبات النفسي ونتخذ من أنماط سلوكه واتجاهاته وميوله معياراً للحكم علي سلوكه وهنا تنكون حقائق السلوك التي يتميز بها الانسان من وجود فروق فردية بين الناس ووجود قدر من الثبات النسبي والتغير في سلوك الفرد فان طابق سلوكه توقعاتتا فإننا نقول ان ذللك يتفق وسماته المميزة له واذا لم يطابق سلوكه توقعاتتا عنه فإننا نقول ان سلوكه لا يتفق وطبيعته. ومن الواضح أن المعايير الكلية والجمعية هي موضع اهتمام العلم الذي يعني بالقوانين والمبادئ العامة بينما المعايير الفردية فإنها تردنا الي مفهوم العلم الذي يهتم بدراسة الحالات الفردية وسيكولوجية الثخصية لا يمكنها أن تقوم علي العموميات وحدها ولا علي الخصوصيات وحدها وانما تشغل مكاناً وسطاً بينهما تقيد كل منهما علي السواء. ويقبل ألبورت منل هذا الرأي ولكن مع توكيد أنه رغم أن الفرد له صفات وخصائص مشتركة مع جميع أفراد الجنس البشري ومع أفراد الجماعة التي ينتمي اليها الا أنه ينسجها جميعاً في نظام فريد منميز فالثخصية اذن هي نظام كلي موحد. وقد ذهب "كلاكهون ومورى وشنيدر" الي أن تكوين الثخصية يمكن النظر اليه في هي ضوء محددات أربعة وما بينها من تفاعلات وهذه المحدات الأربعة هي: 


\section{ILA الجمعية المصرية للقر اءة والمعرفة عضو الجمعية الدولية للمعرفة}

$$
\begin{aligned}
& \text { ( ) المحددات التكوينية (البيولوجية). } \\
& \text { r) محددات عضوية الجماعة. } \\
& \text { r) محددات الدور الذي يقوم به الفرد. } \\
& \text { ع) محددات الموقف. }
\end{aligned}
$$

أولاً: المحددات التكوينية للثخصية: يميل علماء النفس الي توكيد أن الطبيعة الانسانية

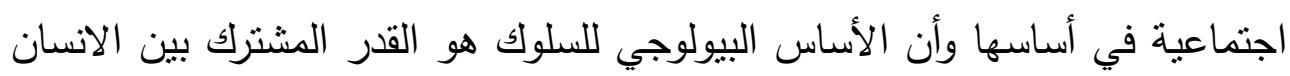

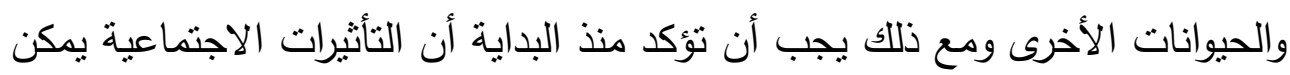

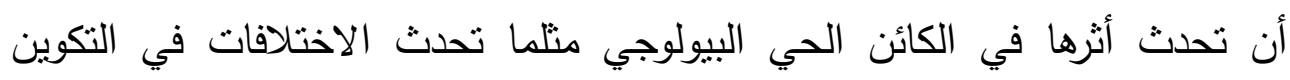

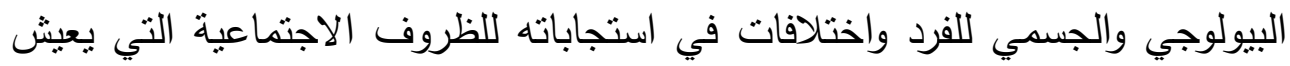

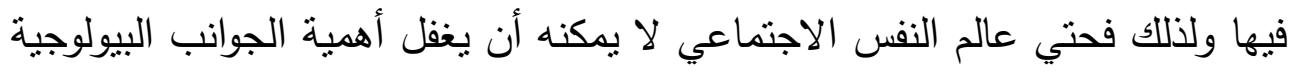
في دراسة الثخصية.

ويقصد بالمحدات التكونية للثخصية الخصائص الجسمية البيولوجية لفرد ما وهذه

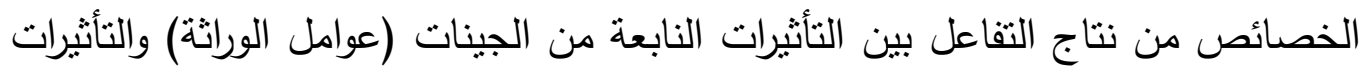

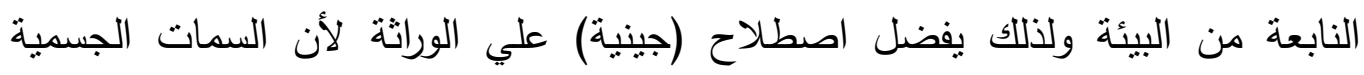

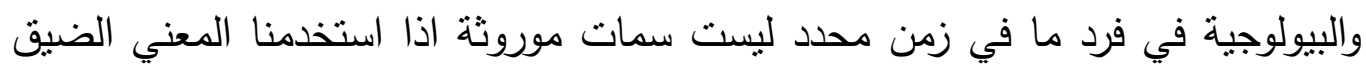
لكلمة وراثة وانما هي محصلة سلسلة طويلة من التفاعلات المعقدة بين الامكانيات

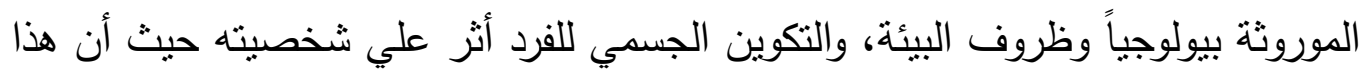
التكوين يؤثر في علاقاته مع الاخرين وفي سلوكه بوجه عام.

ان الكائن الحي يمثل وحدة متكاملة لا يمكن الفصل فيها بين مكوناته البيولوجية

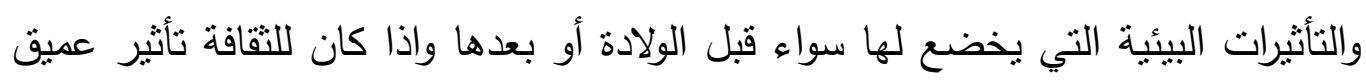

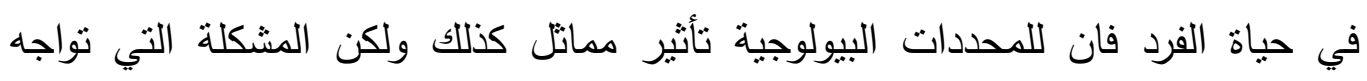

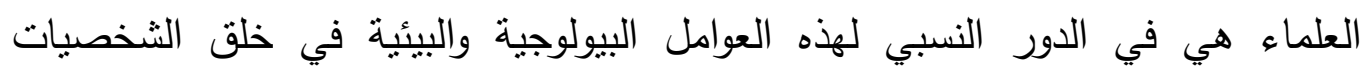




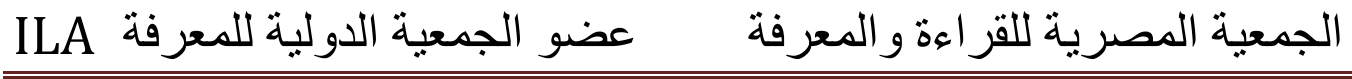

المتمايزة أما أنصار الاتجاه البيولوجي فهم أقرب الي توكيد العوامل البيولوجية علي البيئية بينما أنصار الاتجاه الاجتماعي أكثر توكيداً للعوامل البيئية منهم للعوامل البيولوجية. ثانياً: محددات عضوية الجماعة: ان من المتعذر علينا تفسير سلوك الفرد ونمو شخصيته دون أن ندخل في الاعتبار البيئة التي نشأ فيها ولسهولة دراسة هذه المؤثرات في الثخصية قسم "لويس ثورب" البيئة الي أقسام ثلاثنة هي في الحقيقة مترابطة بشكل وثيق وهذه الأقسام هي البيئة الطبيعية والثقافية والاجتماعية. أما البيئة الطبيعية فيتضح أثرها اذا نظرنا الي اختلاف أساليب تكيف الناس ومعيشتهم وطرق مواجنهم للحياة في البيئات المختلفة فعلي الرغم من تشابه الناس في

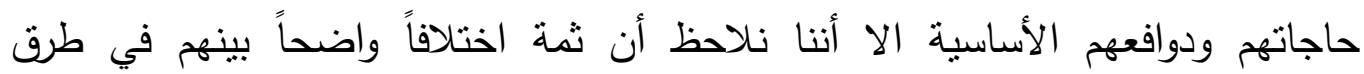
مواجتهم واثباعهم لهذه الحاجات فالبدو في الصحراء والأسكيمو في المناطق القطبية هم الي حد بعيد نتاج هذه البيئات الطبيعية المختلفة فنمو أجسامهم وطرق معيشتهم وأساليب

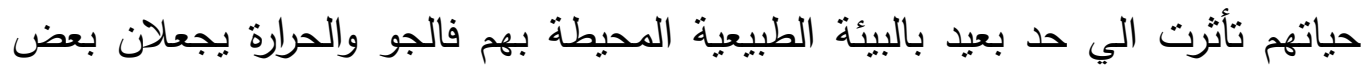
الناس سمر البشرة علي حين يجعلان البعض الاخر بيض البشرة. أما البيئة الثقافية فلها تأثير واضح جداً في نمو الثخصية فأثز الثقافة في تكوين الثخصية لا يمكن أنكاره والبيئة الثقافية أو الحضارة التي تتبع من البيئة يعتبرها البعض

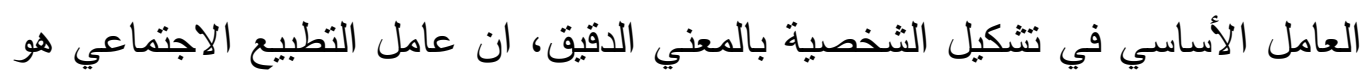
الذي يحول الفرد من كائن حي بيولوجي الي كائن حي اجتماعي يعيش في بيئة يؤثز فيها

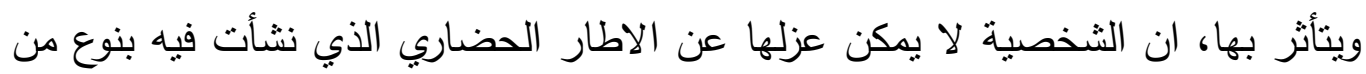
الجراحة التي تقضي علي حياة الفرد.

ثالثاً: محددات الدور الذي يقوم به الفرد: تعد محددات الدور فئة خاصة متفرعة من المحددات العضوية في الجماعات ومن أهم محددات الدور التي نعنيها تلك المتعلقة بالسن والنوع أو العضوية في طائفة أو طبقة أو فئة مهنية معينة والمعروف أن أداء 


\section{الجمعية المصرية للقر اعة والمعرفة عضو الجمعية الدولية للمعرفة}

دور معين لفترة طويلة له تأثير بالغ علي الثخصية، وتتبلور وجهة النظر الثقافية للدور في تلك التعريفات التي تحدده بأنه الأنماط المعيارية الثقافية ومن بين هذه التعريفات يبرز تعريف " رالف لينتون " وقد عرف الدور بأنه المجموع الكلي للأنماط باط التقافية المتصلة بمركز معين وبهذه المعالجة فان الدور يعد مظهراً دينامياً للمركز كما اتضح أن له علاقة واضحة بالمعايير السلوكية أي أن الدور من وجهة نظر دئر لينتون يتكون من الاتجاهات والقيم والسلوك الذي يعنيه المجتمع لأي فرد من الأفراد

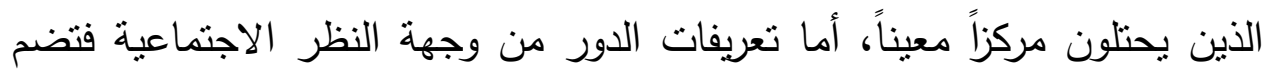
تلك التعريفات التي تركز علي ابراز الناحية السوسيولوجية وتعالج الدور علي أن مفهوم الفرد لمواقفه في ضوء مركزه الاجتماعي بالإضافة الي مراكز الاخرين

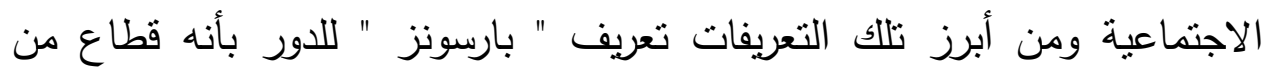
النسق التوجيهي الكلي للفرد الفاعل وهو ينتظم حول التوقعات في علاقتها بمحتوي تفاعلي معين تلك التوقعات التي تتكامل مع مجموعة بعينها من المعايير القيمية التي تتحكم في التفاعل مع واحد أو أكثر من التغيرات في الأدوار التكميلية المناسبة ، ان الدور الاجتماعي هو السلوك المتوقع المرتبط بالمركز الاجتماعي والمركز ببساطة هو بطاقة التعرف أو وسيلة التعرف علي دور اجتماعي معين وهكذا فان مركز الطبيب يعين له اطار من السلوك المتوقع منه كطبيب أي دور الطبيب ولكي نحلل المركز الاجتماعي علينا أن نذكر الملامح الجوهرية للسلوك المتوقع الذي بسمي بالدور •

ان الثقافة هي التي تحدد المركز والأدوار ولهذا تختلف المحددات من مجتمع لأخر تبعاً لذلك وتؤثر المراكز والأدوار بصورة مباشرة في تكوين الثخصية ويحتل الفرد في أي مجتمع مراكز اجتماعية مختلفة تقوم علي أساس النوع والسن والأسرة والطبقة الاجتماعية والمهنة والدين والقومية وبحتوي كل مركز علي مجموعة من الأدوار المحددة له والتي 


\section{الجمعية المصرية للقر اءة والمعرفة عضو الجمعية الدولية للمعرفة ILA}

تمثل أنماط النقافات الفرعية التي تشتمل عليها الثقافة الكلية في مجتمع ما كذللك نري أن الدور يمثل الجانب الدينامي للمركز وما يحويه من حقوق وواجبات.

رابعا: محددات الموقف: المعروف أن الانسان يمر في حياته بعدد من المواقف التي تئثنر

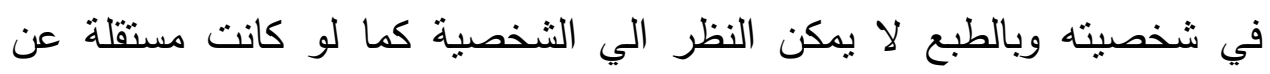

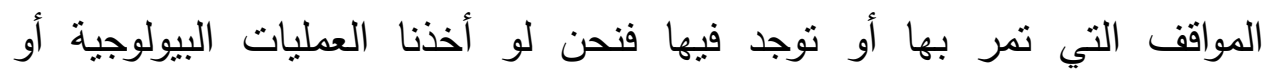

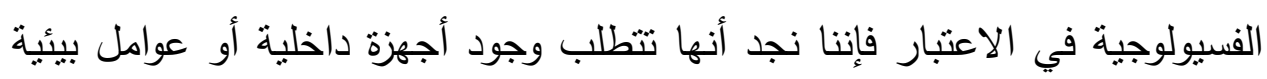

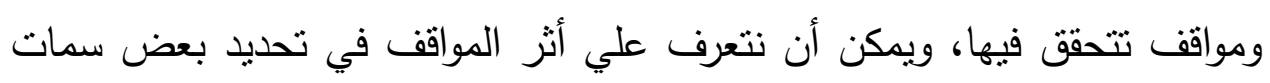

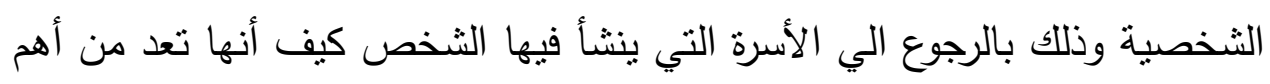

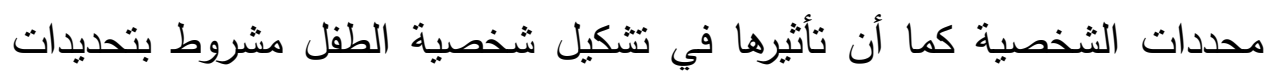

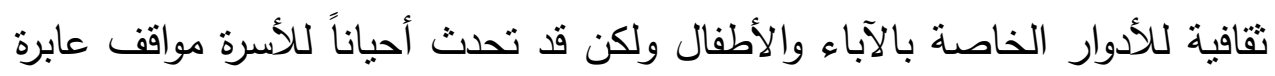

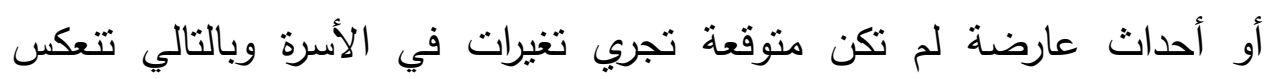
التغيرات في شخصية الأطفال.

وهناك عدة حقائق أثنار اليها "البورت" عند النظر في محددات الموقف من أهمها

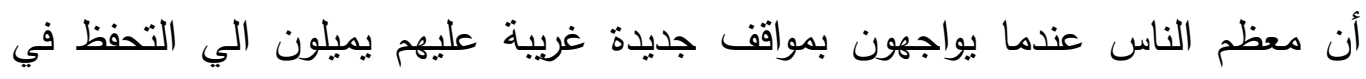

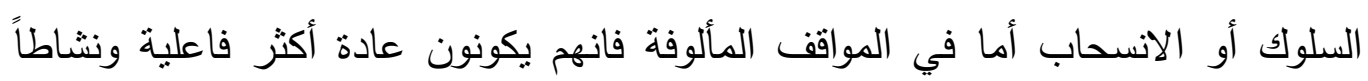
وتتعبيراً عن أنفسهم. الانه.

الثخصية المصرية:

ان الثخصية عالم صغير يعكس ملامح العالم الكبير الثقافي - الاجتماعي الذي

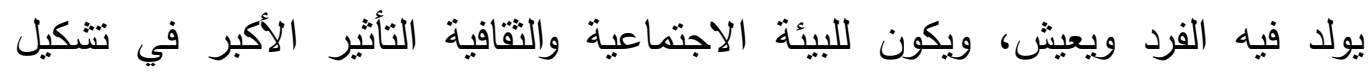

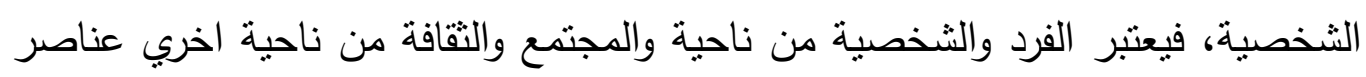

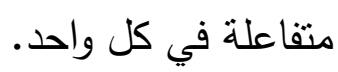




\section{الجمعية المصرية للقر اعة والمعرفة عضو الجمعية الدولية للمعرفة المي}

تعتبر الثخصية المصرية شخصية متغيرة وليست شخصية جامدة فهي تتواكب مع تطور الأحداث وتنتجيب للتغيرات والعوامل المختلفة التي تؤثر في واقعها سواء كانت عوامل اجتماعية أو سياسية أو اقتصادية أو غير ذلك، وهي شخصية تسمح بالتتوع والتعدد وتستطيع التعامل مع ذلك وتتقبله ولهذا يمكن وصفها أحيانا بأنها شخصية معقدة ومركبة وهي برغم أنها شخصية متغيرة الا أن هذا التغير يحدث عادة بشكل بطئ نسبيا وعبر مدى أمني ممتذ.

برغم وجود تباين بين فئات المجتمع وشرائحه الاجتماعية والاقتصادية إلا أنه توجد عدة سمات عامة في الثخصية المصرية من هذه السمات أن الانسان المصري تتسم شخصيته بالتصلب النسبي وعدم قبول التغير السريع والميل الي التمسك بالتراث وعدم قبول التجديد بسهولة.

الثخصية المصرية تمتص من الثقافات الاخرى العناصر التي تتكيف معها فقد امتصت من التقافة الاسلامية عناصر كثيرة واتصلت بالحضارات اليونانية والفارسية كما اخدت من الحضارة العثمانية وبعض هذه العناصر ترتب عليها اثار سلبية والبعض انتج اثار ايجابية، فالثخصية المصرية ليست بناء جامد بل تقبل التطوير .

وقد ساهم الجغرافيون المصريون في دراسة الشخصية المصرية واشهر هؤلاء (سليمان حزين، مصطفي عامر، جمال حمدان)، وابرز هؤلاء دور العوامل الجغرافية في تشكيل شخصية المصريين ابتداء من البيئة المحلية والنيل والمكان والموارد الطبيعة والمناخ واحتكاكات المصريين بالعالم الخارجي، وأكد هؤلاء الجغرافيون اثر هذه العوامل الجغرافية في تشكيل سلوك المصريين وأفعالهم وثقافتهر.

ومن الدراسات التي قامت ببحث الثخصية المصرية وسماتها دراسة "سامية خضر" والتي كان من أهم النتائج التي توصل اليها البحث ان الثخصية المصرية: 


\section{ILA الجمعية المصرية للقر اءة والمعرفة عضو الجمعية الدولية للمعرفة}

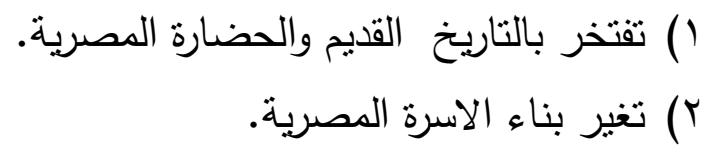

r) انعكاس اثار الاقمار الصناعية علي الثخصية المصرية.

ع ) تباين مواقف افراد العينة من المشاركة السياسية ما بين مشارك ولا مشارك

ومتردد.

0) ابانت الدراسة ان اهم معوقات الانطلاق نحو المستقبل هي الامية والفقر

والمرض والظلم الاجتماعي والنظام الاقتصادي الرخو واسرائيل.

وفي عام به9 ا نشر "سمير نعيم" في مجلة البحوث الاجتماعية بحث بعنوان "أثنر

التغيرات البنائية في المجتمع المصري خلام حقبة السبعينات علي أنساق القيم الاجتماعية

ومستقبل التتمية".

وقد بين فيه اعتماداً علي الوقائع والبيانات النوعية القيم المنشرة في المجتمع المصري وتأثيرها علي السلوك الفعلي لقطاعات عريضة من المجتمع في كافة مجالات

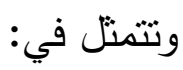

( ) الكسب السريع والسهل وليس علي العمل المنتج وبذل الجهد فيه.

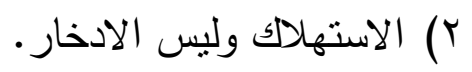

r) الاهتمام باللحظة الراهنة وليس علي الاهنمام بالمستقبل البعيد والتخطيط

.4

ع) تقدير المنتجات الأجنبية المستوردة واحتقار المنتجات الوطنية المحلية.

0) الهروب من مواجهة الواقع والتصدي لتغيره عن طريق الهجرة مثنا.

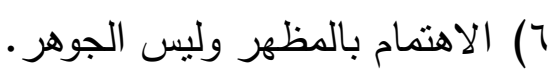

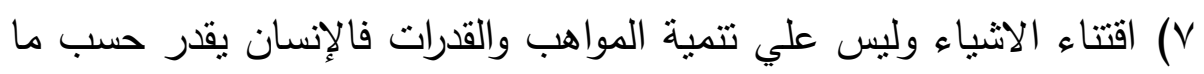

يقتي وليس حسب ما يتمتع به من امكانات عقلية وخلقية. 


\section{ILA الجمعية المصرية للقر اءة والمعرفة عضو الجمعية الدولية للمعرفة}

\section{^) الأخذ لا العطاء.}

9) اللامبالاة والسلبية وليس القدرة علي ابتكار الحلول والابداع. • (1) الحقد الطبقي وليس علي المساواة والمحبة والإخاء.

(1) الحث علي الفساد الخلقي بجميع صوره فالغاية تبرر الوسيلة. r ( ) اللاعقلانية وليس علي العقلانية.

r ( ) استباحت واهمال الملكية العامة لحساب الملكية الخاصة. ع ( ) اعلاء المصلحة الثخصية علي المصلحة القومية والوطنية.

وقد ذكر "سمير نعيم" انه قام بجمع ما استطاع من السمات الثخصية التي نسبت للإنسان المصري سواء من قبل الرحالة الذين زاروا مصر أو من الاجانب الذين عاشوا

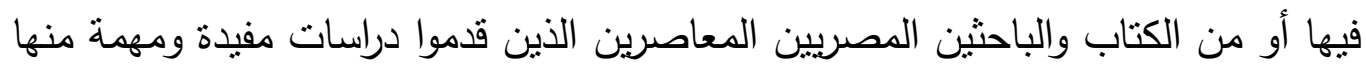
ما يقدم تحليلات وتقسيرات لسيادة أو انتشار هذه السمات في المجتمع المصري، والتي تتسم بالعمق وتربط بين شيوع هذه الصفات وبين الاحوال السياسية والاقتصادية والاجتماعية للمجتمع المصري وتعرض بشكل منوازن السمات السلبية والايجابية في ذات الوقت وهي كثيرة ومتتوعة ولكنها تتفق جميعا في انها تتسب للمصريين بوجه عام دون اي تمييز وهي سمات عامة ودائمة في ماعدا قلة قليلة حددت فئات بعينها من المصريبن ونسبت اليهم سمات خاصة.

\section{من العوامل المؤثرة في تغير الثخصية المصرية:}

() التقدم التكنولوجي والتطور المطرد في تكنولوجيا تبادل المعلومات والاتصال تحديدا وما أفرزته من تغيرات في الثقافة المجتمعية ومما أدت اليه من اختزال للمسافات والأزمنة والفواصل الجغرافية والحدودية بين البشر في مختلف أنحاء الأرض وما ارتبط بذلك من مستجدات في التقافة المصرية علي النحو الذي ولي يؤثر في الثخصية المصرية. 


\section{الجمعية المصرية للقر اعة والمعرفة عضو الجمعية الدولية للمعرفة}

r) العولمة وما يرتبط بها من عوامل اقتصادية واجتماعية وسياسية وتغيرات طرأت علي مجتمعات ودول العالم كلها مما أدي الي حتمية قبول التغيير علي مستوى المجتمع والواقع المحلي فالعالم الكبير تحول الي قرية صغيرة. r) الأوضاع الاقتصادية وخاصة تحول الاقتصاد نحو الخصخصة الي جانب الأوضاع السياسية والاجتماعية التي يمر بها المجتمع المصري والدعوة الي تبني حركة الاصلاح الاجتماعي الثامل. ع) تغير العلاقة مع الاقليم في مصر والذى ظهر منذ بدأ التحول واضحا من الريف الي الحضر ومن المدينة الي ضواحي المدن ومن الوادي الي البحر حيث مزيد من الاحتكالك والانفتاح علي العالم الخارجي.

غيرت العولمة من الملامح العامة للشخصية المصرية وتمثل العولمة منعطفا تاريخيا جديدا يختلف عن الأطر التاريخية السابقة، فالعولمة ارتبطت بالأساس بالبعد

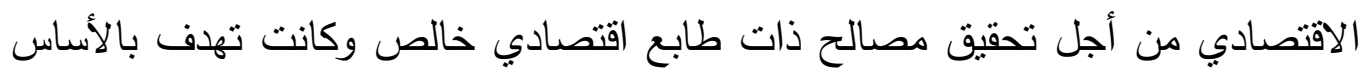
الي حل مشكلات خاصة بالمجتمع الأمريكي فالمرجو هنا أن المدخل الأساسي للعولمة هو المدخل الاقتصادي ولكن دخول المجتمع المصري في سياقات العولمة أبرز تغيرات علي ملامح الثخصية المصرية وأثز بشكل أو بآخر علي ملامح الهوية خاصة وأن القيم المادية للعولمة شهدت تتاميا علي سطح المجتمع بما جعل هذه القيم تمنل العامل الأساسي في حياة المصري المعاصر بما أثر علي منظومة القيم غير المادية والتأثير علي الهوبة.

تعقيب:

ان الثخصية من الموضوعات المعقدة والتي قد تكون مثيرة لدراستها والتعرف عليها لما يحاوطها من غموض فالنفس البشرية بها الكثير من الأسرار والتي مازال الباحثون يحاولون التعرف عليها. 


\section{الجمعية المصرية للقر اعة والمعرفة عضو الجمعية الدولية للمعرفة ILA}

وقد سردت الباحثة بعض تعريفاتها وأوضحت مكونتها ومحدداتها، أيضاً قامت الباحثة بذكر سمات الشخصية المصرية من خلال بعض الدراسات والبحوث ويجب الذكر أنه سمات الشخصية في أي مجتمع نتشمل علي بعض السمات الايجابية وبعض السمات السلبية، وعرض السمات السلبية يهدف الي التعديل والاصلاح بهدف التتمية. وقد لاحظت الباحثة تشابه بين بعض السمات الثخصية التي ذُكرت في بعض الدراسات وبين الثخصية المصرية في وقتنا الحالي، فقد مازالت بعض السمات الثخصية مستمرة حتي اليوم ويتوارثها أفراد المجتمع من خلال عملية التنشئة الاجتماعية سواء داخل الاسرة أو في المجتمع بالاحتكاك مع أفراده أو من خلص عملية التعليم. 


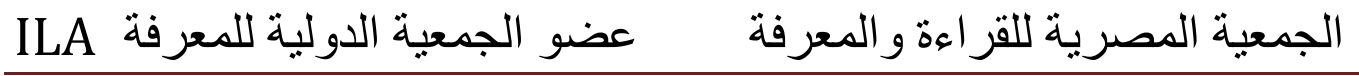

\section{المصادر والمرلجي}

( ) عبد الباسط عبد المعطي، الأنماط المتغيرة للتنين والثخصية المصرية استطلاع جدلية التأثيرات

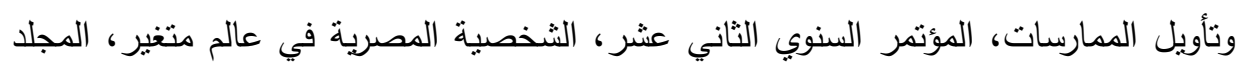

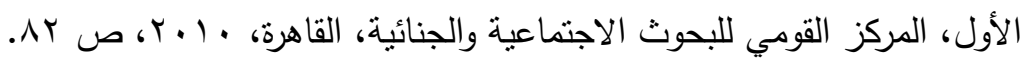

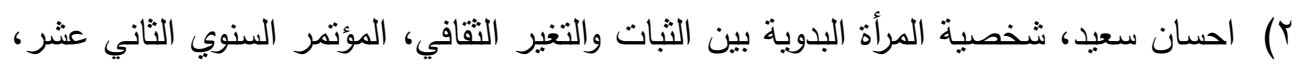

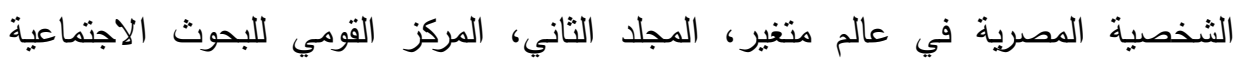

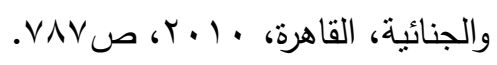

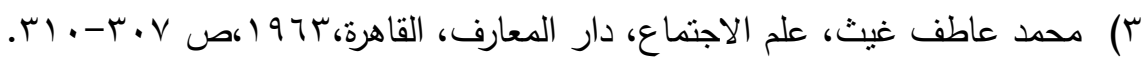
ع) علياء شكري، قضايا المرأة المصرية بين التراث والواقع: دراسة للثبات والتغير الاجتماعي

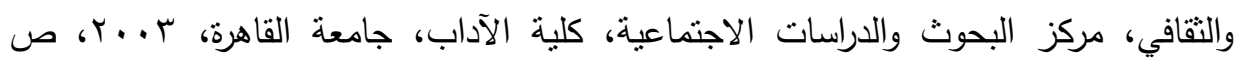

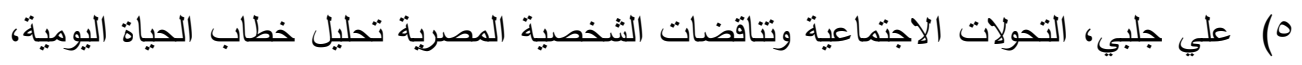

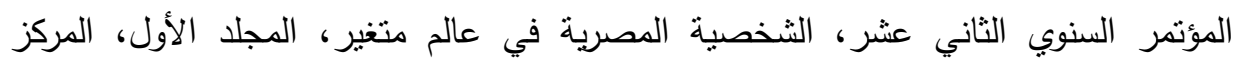

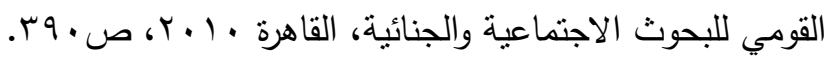

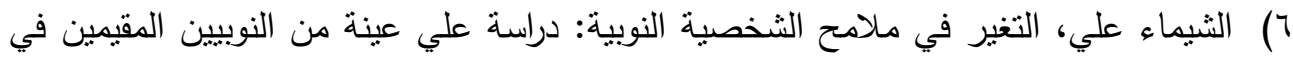

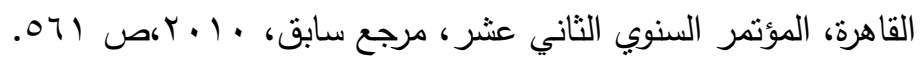
V فاروق مصطفي، الثخصية القومية وتأثرها بالبطل الأسطوري: دراسة تحليلية، المؤتمر السنوي

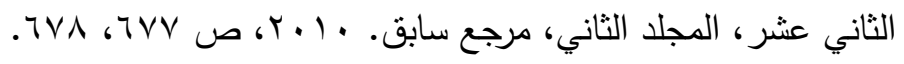

^) سعيد فرح، الثخصية القومية بين الحقيقة والوهم في عصر العولمة، المؤتمر السنوي الثاني

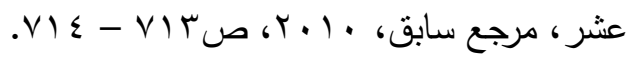
9) أحمد عبد الموجود، الثخصية البدوية المتغيرة دراسة أنثروبولوجية لبدو سيناء، المؤتمر السنوي

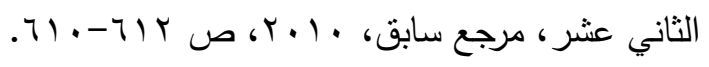




\section{الجمعية المصرية للقر اعة والمعرفة عضو الجمعية الدولية للمعرفة ILA}

• (1) ميساء عبد اللطيف محمد، أساليب التنشئة الاجتماعية الخاطئة وأثزها علي التوافق النفسي والدراسي لتلاميذ مرحلة الأساس بمدينة زالنجي، رسالة ماجستير، كلية الدراسات العليا والبحث

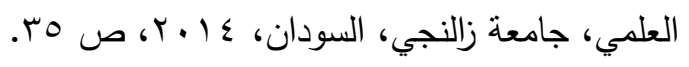

1) منصور حسين، محمد مصطفي زيدان، الطفل والمراهق، مكتبة النهضة المصرية، بA19 ص ص

12) Carlson Neil R * the science of behavior: the psycho dynamic approach، Toronto: Pearson Canada، 2010، p 453.

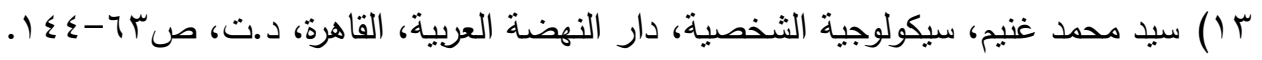
ع (1) سامية خضر، تحديات الحاضر وافاق المستقبل، الثخصية المصرية في عالم متغير،أعمال

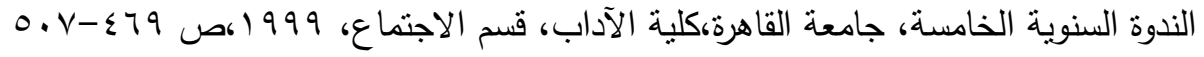
1) سمير نعيم، السمات الثخصية للمصريين بين الثبات والتغير، المؤتمر الثانوي الثاني عشر،

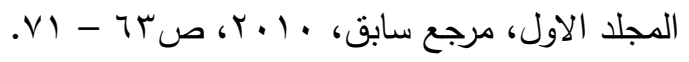

צ (1) مها عبد المجيد، تعقيب، خبير المركز القومي للبحوث الاجتماعية والجنائية، القاهرة، • ( • ب، ص ז 